\title{
Home Environment and Parental Involvement in Homework During Adolescence in Catalonia (Spain)
}

\author{
Toni Mora ${ }^{1}$ and \\ Josep-Oriol Escardíbul?
}

\begin{abstract}
It is well documented that parental behavior is a strong determinant of a child's educational achievement and general well-being. Thus, it seems relevant to analyze the determinants of parental involvement in the education of their children. While most studies analyze the effect of family characteristics (such as parents' education, ethnicity, or family structure) on parental involvement, we focus on the effect of home environment. Specifically, we consider parental assistance in homework during adolescence, which is defined from the children's perspective. Data come from a unique sample of more than 2,300 students in the last 2 years of compulsory education in 70 schools in Catalonia (Spain). Results show that a good home environment increases the relative probability that parents get involved in their children's homework. The effect is slightly higher for girls than for boys. The inclusion of home environment leaves no relevance to family structure. Results are robust to different estimation procedures.
\end{abstract}

\section{Keywords}

educational achievement, parent support, families

\section{Introduction}

Since the publication of the Coleman report, researchers have shown that parents are important actors in the production of education (Coleman et al., 1966), and today it is well established that parental effort makes a difference in educational outcomes and, in general, child well-being. Indeed, the majority of studies predict greater academic achievement when parents are actively involved in their children's educational process, either through their relationship with teachers and the school or through their support of learning at home (Dearing, Kreider, Simpkins, \& Weiss, 2006; De Fraja, Oliveira, \& Zanchi, 2010; Flouri \& Buchanan, 2004; Gelber \& Isen, 2013; Houtenville \& Conway, 2008; Katz, Kaplan, \& Buzukashvily, 2011; Walsh, 2010).

One way of supporting learning at home is to help children with their homework. Today, parents seem to understand that student academic achievement is correlated to homework completion, and, indeed, most parents are in favor of students doing academic homework after school. As a result, parents involve themselves directly in their children's homework (Duffet \& Johnson, 2004; Hoover-Dempsey et al., 2001). In this regard, Cooper (1989); Cooper, Robinson, and Patall (2006); and Di Pietro and Cutillo (2006) show that students who do homework have better school outcomes than those who do not, and Johnson and McComb (2008) stress that homework provides many other educational benefits for students, such as developing good study habits or fostering responsible character traits and independent lifelong learning. Moreover, homework can also give parents an opportunity to see what their children do at school, serving as a vital link between schools and families, and increasing communication between parent and child (Cooper et al., 2006).

It is therefore interesting to identify the factors that induce parents to allocate greater amounts of time to the educational process of their children in general, and to homework in particular. In an attempt at moving beyond the traditional nature-nurture debate and the associated examination of social environment factors, in line with Canova and Vaglio (2010), we seek to identify within-family influences, that is, a child's home inputs, as a harmful home environment affects children's behavior and their attitude toward learning (Todd \& Wolpin, 2007). Most of the related literature considers the effect of family characteristics on parental involvement in homework (see "Literature Review" section). For this reason, we propose an 
analysis that focuses not on the structural characteristics of the family but rather on one factor related to the household dynamic, such as the home environment. Specifically, this article examines the effects of the home environment on parental involvement in homework during adolescence in Catalonia (Spain), where the former is defined as the degree of satisfaction expressed by the children with the home environment.

According to the literature, a consideration of children's perceptions of family education could be important for understanding the relationship between educational practices and students' academic performance (Linver, Barber, \& Eccles, 1997; Oubrayrie-Roussel \& Safont-Mottay, 2011). As Balli (1998) reports, students feel they do better at school when parents help. Moreover, students may consider homework to be more pleasant if their parents are involved, as they may be more attentive and adopt a more positive mood (Katz et al., 2011; Leone \& Richards, 1989), derive greater enjoyment from homework (Shumow, 1998), and perceive homework activities as easier to solve (Frome \& Eccles, 1998). In addition to homework, S. Irwin (2009) points out that for young people, family emotional support is important and highly valued by teenagers in their perceptions of what it takes to get on in life. Therefore, as student perceptions of parent involvement in education may change their attitude and behavior with respect to homework and academic achievement, it seems relevant to analyze the role of the home environment as a determinant of parental involvement in homework from the students' point of view. We expect a positive perception of the home environment among Catalan adolescents to relate positively with parental involvement in homework, in line with the literature that shows that non-conflict households encourage student academic achievement (Todd \& Wolpin, 2007).

Finally, we split the analysis by gender. It is relevant to consider boys and girls separately, as their perceptions may be different. As Kristjansson and Sigfusdottir (2009) and Duchesne and Ratelle (2010) show, compared with boys, girls perceive their parents to be more supportive. Moreover, Cummings et al. (1994) and Sorbring, Rödholm-Funnemark, and Palmérus (2003) report that there are gender differences in children's reactions to changes in home environment. From the parents' point of view, fathers and mothers may interact differently with their sons and daughters. Thus, familial practices are often profoundly gendered in terms of relationships and roles (Morrow, 2006). However, parents may reinforce or discourage specific behaviors (Leaper, 2000). In respect to education, Deslandes and Cloutier (2002), for instance, show gender differences between adolescents with respect to parental involvement in schooling (not only homework), with girls being more willing to accept parental help than boys (Shek, 1999). Likewise, Bonesrønning (2010) points out that girls report somewhat higher parental effort than boys in homework assistance.

We highlight the following contributions of our study. First, to the best of our knowledge, no evidence has previously been presented in the literature about the impact of the home environment on parental involvement in homework assistance (conditioned to family structure). Second, as reported by Turtiainen, Karvonen, and Rahkonen (2007), we consider aspects of family life as perceived by young people themselves, a perspective that is analyzed in very few studies. Third, we use a unique data survey containing information about parental involvement in homework assistance and an extensive list of covariates describing the following three levels of characteristics: individual, scholar, and parental. Finally, although we use cross-sectional data, we are able to consider two specific student traits (conscientiousness and motivation) that both capture individual heterogeneity, and moreover, we apply the method of instrumental variables (IV) to infer causality.

Our results show that adolescent perceptions of a good home environment increase the amount of homework assistance from parents. Likewise, female students perceive that household environment has a higher effect on receiving homework assistance. Finally, the study shows that the home environment is more important than family structure as a determinant of parental involvement in their child's homework.

The "Literature Review" section summarizes previous theoretical and empirical evidence of parental involvement in homework. Then, the database and the econometric strategy are described, and our main results are shown. Finally, the last section concludes.

\section{Literature Review}

In this section, we consider main studies that analyze parent's involvement in their child's homework as well as the determinants of this involvement.

From a theoretical approach, Grolnick and Ryan (1989) consider three dimensions of parenting style as predictors of children's self-regulation and competence: autonomy support, direct parent involvement, and provision of structure. The former is defined as the degree to which parents value and use techniques which encourage independent problem solving and decision making. Direct parent involvement refers to a style adopted by parents who want to take an active part in the child's life. Finally, the provision of structure refers to the degree to which parents provide clear and consistent guidelines and follow through on contingencies for the child's behavior. Cooper and Lindsay (2000) apply this theoretical framework to 
homework in their empirical research conducted in the United States. The authors conclude that autonomy support is positively related to the completion of homework and results on standardized tests, whereas parents' direct involvement is statistically negatively related to the latter. In their review of studies, Cooper and Lindsay show that although parents are aware that some kinds of involvement can be counterproductive to their children's learning, they understand that supporting autonomous behavior and providing structure, motivation, and competent mentoring can make positive contributions to their child's learning.

Thus, parental involvement in child's homework is a complex relationship, and only some actions lead to positive effects regarding children's educational attainment as well as other benefits (Cooper, 1989; Patall, Cooper, \& Robinson, 2008). It is, therefore, interesting to identify which factors drive parental involvement. Most studies consider parental background, which includes the role played by mothers, ethnicity, and family structure. With respect to the former, mothers play a leading role in the educational process as they tend to dedicate more time to their children's schooling than fathers do, although this gap is narrowing, and the recent literature indicates that this is a somewhat debatable issue (Bianchi, 2000; Holmlund, Lindahl, \& Plug, 2011; Sayer, Bianchi, \& Robinson, 2004). As for the characteristics of the mother, more highly educated women spend more time on child care than their less educated counterparts do (Guryan, Hurst, \& Kearney, 2008; Gutiérrez-Domènech, 2010; Rønning, 2011). Other studies argue that the amount of time is not important and that what counts is the quality of the activities mothers engage in with their children (see Bianchi, 2000, for a review).

In studies of ethnic background, Aldous (2006), for example, reports differences between families belonging to different ethnic groups. However, regardless of ethnicity, parents' educational aspirations for their children as well as the children's own aspirations are also, in general, positively related to their academic achievements. In studies of family structure, divorced families seem more likely to allocate less time to assisting their children's educational process, either as a consequence of damage to the parentadolescent relationship (Amato \& Sobolewski, 2001) or because it negatively affects the family's economic resources (Francesconi, Jenkins, \& Siedler, 2010; Sanz-de-Galdeano \& Vuri, 2007). Indeed, there is a general consensus as to the negative impact of non-intact families (not formed or unstable) on children's behavior and well-being as well as on their educational attainment (Amato, 2000; Amato \& Keith, 1991; Francesconi et al., 2010; Ginther \& Pollak, 2004; Lansford, 2009; Teachman, 2008). However, Burnett and Farkas (2009) show that the correlation between family structure and children's school achievement is largely spurious, due, instead, to child and other family characteristics.

Yet, not only family structure and other characteristics of parental background need to be taken into consideration when analyzing parental involvement. An intact family does not necessarily guarantee a healthy environment for children, as there may nevertheless be constant parental arguments in the home. Divorce and other instability factors aside, children might be exposed to levels of parental conflict that have an impact on their educational outcomes and adolescent behavior (Amato \& Kane, 2011; Crosnoe \& Elder, 2004; Dotterer, Hoffman, Crouter, \& McHale, 2008; Melby \& Conger, 1996; Musick \& Meier, 2010). In line with these arguments, reduced efforts in monitoring children's education can be expected in association with poor parenting quality. Likewise, Dotterer et al. (2008) show that not only parent-adolescent conflict is related to lower grades at school but also lower grades predict future conflicts between parents and their adolescent offsprings.

Here, we seek specifically to examine the effects that arise out of the home environment itself as opposed to those attributable to its structure or background. Our line of argument is that although non-intact families clearly have an impact, the household atmosphere is relevant in that it can also alter children's behavior. As indicated in the introduction, we focus on parental involvement during adolescence, a critical period of development in which young people are exposed to many new situations: continually adjusting to physical changes, exploring their sexuality, establishing their personal identity, seeking greater independence from their families, and increasingly relying on peers (C. E. Irwin, Scott, \& Uhler, 2002). At the same time, parents modify their roles to allow their children to develop their own self-identity. Indeed, parental involvement practices decline during adolescence (Milgram \& Toubiana, 1999). For this reason, we strictly limit our analysis to those students attending the last 2 years of compulsory schooling (Grades 9 and 10 equivalent), given that some parents may well decide to stop providing their children with homework assistance once they achieve the minimum legally required level of education.

\section{Data and Econometric Specification}

The data for this analysis are drawn from a sample of secondary school students in Catalonia (a region that has one of the highest GDPs per capita in Spain). The data sampling took place between February and June 2008. We restricted the sample to two specific age cohorts, both enrolled in compulsory secondary education. This enables us to consider individuals from a sample of students of similar ages and who do not, therefore, suffer any effects attributable to differences across early and middle adolescence. We chose 
a school sample representative of the total population of Catalan high schools based on their ownership characteristics (public and private schools). The final sample contained information for more than 2,300 students at 70 high schools.

The questionnaire was supplied online. Given that not all the high schools had computer room facilities or sufficient time schedules, some of those who agreed to participate received the questionnaire in paper format (around 15\% of respondents). The questionnaire contained several blocks of questions: student personal data, conscientiousness and motivation questions, parental background information, lifestyle conditions, scholar features, and school

Table 1. Responsible for Helping Students With Their Homework.

\begin{tabular}{lcccc}
\hline & & Female & Higher \\
& Full sample & students & educated mothers & Employed mothers \\
\hline Nobody & $1,216(44.8)$ & $589(41.6)$ & $331(45.0)$ & $824(44.4)$ \\
Friends & $97(3.6)$ & $58(4.1)$ & $16(2.2)$ & $73(3.9)$ \\
Private tutoring & $424(15.6)$ & $215(15.2)$ & $86(11.7)$ & $275(14.8)$ \\
Relatives and siblings & $387(14.3)$ & $231(16.3)$ & $97(13.2)$ & $275(14.8)$ \\
Father or mother & $390(14.4)$ & $213(15.0)$ & $124(16.9)$ & $263(14.2)$ \\
Both parents & $202(7.4)$ & $110(7.8)$ & $81(11.0)$ & $145(7.8)$ \\
\hline
\end{tabular}

Note. We report absolute frequencies for each category with relative frequencies in parenthesis.

characteristics. None of the students had access to the questionnaire prior to responding which enabled us to avoid any attrition effects, but students were free not to respond to some questions.

Table 1 shows the descriptive results indicating the source of homework supervision received by the adolescent students. Our descriptive results indicate that $44.8 \%$ of the sample does not receive any assistance (from parents or someone else), $15.6 \%$ receive private tutoring, $14.3 \%$ is helped by relatives, and $3.6 \%$ by friends. The percentage of adolescent students obtaining assistance from one or both parents is $21.8 \%$. We also show some descriptives considering subsamples. Thus, the percentage of female students receiving parental assistance is slightly higher (22.8\%). This proportion is even higher when we include the condition that the mothers have attained higher education qualifications (27.9\%), but this is not the case for those in employment (22\%).

Our data may allow us to estimate a multinomial logit where the dependent variable has several categories, one for each type of homework assistance received (from friends, private tutoring, relatives, or parents) as well as one value when no assistance is received. However, as the parallel regression assumption is rejected $\left(\chi^{2}=356.37 ; p\right.$ value $\left.=.00\right)$, we finally opted to estimate a logit model with a dichotomous dependent variable $\left(y_{i}\right)$. Thus, for the dependent variable, " 1 " represents those adolescents that received parental homework assistance and " 0 " represents those that received any other type of support or who did not receive any assistance at all (see Equation 1):

$$
P_{i}^{*}=\left\{\begin{array}{ccc}
1 & \text { if } & \hat{H}_{i}^{\prime} \beta+x_{i}^{\prime} \delta+\varepsilon_{i}>0 \\
0 & \text { otherwise }
\end{array} .\right.
$$

In this model, $P_{1}^{*}$ is a dichotomous latent variable, which accounts for parental involvement in homework supervision. $P_{i}^{*}=1$ in the case of an individual $i$ being supervised by his or her parents. $H_{i}$ represents the home environment, $x_{i}$ is the $\mathbf{k}$-vector of instrumental explanatory variables, $\delta$ is a $\mathbf{k}$-vector of unknown parameters such as $\beta$, and $\varepsilon_{i}$ represents the independently distributed random error term. Home environment is understood as a measure of satisfaction with that environment; thus, students were asked, "What is your degree of satisfaction with home environment?" The average value was 4.2 points (measured on a Likert-type scale from 1 to 5). Note that adolescent students living in non-intact households scored an average of 3.9 points. With regard to the relationship between the home environment and homework assistance, students assisted by their parents express a higher degree of satisfaction with their home environment (4.3) than those that do not receive any assistance (4.0), the difference being statistically significant. Likewise, we find sufficient variation in the home environment for the percentage of students reporting parental assistance (the standard deviation was 0.86 ).

As controls, we used a long list of covariates $\left(x_{k, i}\right)$ affecting parental involvement. Table 2 shows summary statistics for these covariates, including adolescent characteristics (such as age, gender, and immigrant status) and student scholar features (school academic year attained, grade obtained in mathematics during the last academic year, the kind of school enrolled in, the time taken to get to school, and student aversion to sharing school notes). Moreover, some family characteristics are observed: the number of older siblings, family structure (defined through parents' civil status), the number of years since 
parents had divorced, difference in age between the mother and the adolescent, mother's educational attainment level, the number of books at home (defined by a dichotomous variable, such as having more than 100 books at home), parents' employment status (if working), students' self-reported perception of parents' health status, and whether the student received any rewards from parents based on school performance. Finally, some class-level characteristics are included: percentage of mothers with university education, percentage of female students, and relative number of immigrants and of divorced parents. The latter allowed us to consider certain class fixed effects recommended for analyses of this type (Jones, Toma, \& Zimmer, 2008; Walsh, 2010).

A further point to note is the inclusion of personality traits (such as school work conscientiousness and student motivation) as proxies for individual heterogeneity. The conscientiousness variable was constructed using factor analysis from the information given by pupils on the questionnaire. We conducted several interviews with psychologists to ensure that relevant questions were included to determine conscientiousness.

Table 2. Descriptive Statistics for Covariates.

\begin{tabular}{lr}
\hline & $M(S D)$ \\
\hline Individual characteristics & $15.55(0.74)$ \\
Age & $0.52(0.50)$ \\
\% being female & $0.10(0.30)$ \\
\% being immigrant & $0.55(0.50)$ \\
\% fourth academic year of compulsory education (Grade 10) & $6.31(1.59)$ \\
Grade in mathematics past academic year (0-10 points) & $0.53(0.50)$ \\
\% attending a private school & $13.85(12.54)$ \\
Time to get to school (minutes) & $2.85(0.83)$ \\
Student states school notes should be shared (1 = completely disagree, 2 & \\
disagree, 3 = agree, 4 = completely agree) & \\
Family characteristics & $0.17(0.37)$ \\
Number of older siblings & $0.23(0.42)$ \\
Parents' civil status: \% not being married & $1.24(3.26)$ \\
Number of years since divorce & $28.57(4.69)$ \\
Differential in years with mother & $0.45(0.50)$ \\
\% mother's attaining secondary education & $0.30(0.46)$ \\
$\%$ mother's attaining tertiary education & $0.48(0.50)$ \\
\% number of books at home above 100 & $0.81(0.40)$ \\
\% father being employed & $0.66(0.47)$ \\
\% mother being employed & $4.12(0.81)$ \\
Father's health status degree (1 = very bad-5 = excellent) & $4.15(0.75)$ \\
Mother's health status degree (1 = very bad-5 = excellent) & $2.42(0.95)$ \\
Receiving an award from parents for doing homework (1-4) & \\
Class-level characteristics & $0.30(0.18)$ \\
\% mother's attaining higher education in the class & $0.51(0.15)$ \\
\% female classmates & $0.10(0.11)$ \\
\% divmigrants in the class & $0.17(0.11)$ \\
\hline
\end{tabular}

questions from the well-known Big Five Personality Traits Test (see Norman, 1963). Specifically, we incorporated the following items: I am exacting in my work; I follow a schedule; I get chores done right away; I pay attention to details; I leave my belongings around; I make a mess of things; and I shirk my duties. With regard to student motivation, 15 specific items (related to the willingness to study mathematics) were considered. In this case, we followed primarily Alonso-Tapia and Arce-Sáez's (1992) specific items for Spanish teenagers. Note that by so doing, we include a measure of ability in the sense of a school skill, which complements the measure of knowledge related to school grades. The present sample is a crosssection, and therefore, we need to control for these psychological traits as Boyce (2010) argues that personality accounts for greater individual heterogeneity than does the inclusion of fixed effects in a panel data approach.

We grouped conscientiousness and motivational items into two unique factors, one for each concept. To measure variability in the resulting dimension, we quantified Cronbach's alpha reliability (.743 and .736, respectively). In addition, the Kaiser-Meyer-Olkin measure of sampling adequacy indicated that multivariate analysis provides excellent results (both factors accounted for $95 \%$ of the overall variability in each concept). Subsequently, we rescaled the factor predictions to [0-1], as the individual opinions should not have a negative value, while " 1 " should represent either being fully confident in oneself or being fully motivated. After showing that its exclusion/inclusion did not affect the rest of the determinants, we 
preferred to include this substitute of ability as biasing effects might be expected when omitting this measure.

However, there might still be some unobserved factors driving both parental involvement and the home environment (or the causality between the home environment and parental involvement in homework might be bidirectional), even though we included an extensive list of covariates. Thus, and given that we are working with observational data, we finally estimated causality using IV. A probit combined with an IV model provides consistent estimations for the dichotomous analysis (here, we used Newey's two-step estimator). As shown in Equation 2, $P_{i}^{*}$ accounts for, as discussed above, parental involvement in homework supervision, $\hat{H}$ represents the predicted perception of the home environment, $x_{k, i}$ is the $\mathbf{k}$-vector of explanatory variables, $z_{i}$ are the IV, $\delta$ are the $\mathbf{k}$-vectors of unknown parameters, and $\varepsilon_{i}$ represents the independently distributed random error term.

$$
\begin{gathered}
P_{i}^{*}=\left\{\begin{array}{ccc}
1 & \text { if } & \hat{H}_{i}^{\prime} \beta+x_{i}^{\prime} \delta+\varepsilon_{i}>0 \\
0 & \text { otherwise }
\end{array} .\right. \\
H_{i}=z_{i}^{\prime} \gamma+\varpi_{i} .
\end{gathered}
$$

The aim was to find an instrument that correlated highly with the home environment but not with parental effort. We used three instruments: a student's self-perception of his or her relationship with the father, a student's self-perception of his or her relationship with the mother (as Amato \& Sobolewski, 2001, point out, parents that argue most frequently with their adolescent children have a weaker relationship and, thus, present a poorer home environment), and the adolescent's state of mind (defined as their mood the day they filled in the questionnaire). All these measures were strongly related to the home environment. The correlation between the home environment and the student's relationship with their father and mother was .60 and .66, respectively, and the correlation between the former and the adolescent's state of mind was .29. However, our proposed instruments did not show a strong link with the dependent variable (parental effort): The correlation coefficients were .10 for the relationship with the student's father, .08 for the relationship with the mother, and -.01 for the adolescent's state of mind. Finally, our instruments performed well in terms of their validity given the following tests: the overidentification test ( $4.26 p$ value $=.12)$, firststage explanatory power $\left(R^{2}=.47\right)$, and there was a similar variance of coefficients between logistic and IV estimations.

\section{Results}

Table 3 contains the logit estimates of the students' perceptions of the home environment on the provision of parental homework assistance. The results are obtained considering robust clustered standard errors at classroom level. We report the results of the marginal effects for ease of interpretation. The first column shows results for the full sample. The other two columns display results for males and females. As expected, home environment is positively associated with parental involvement. Thus, the better the adolescent's perception of the home environment, the greater is the involvement of his or her parents in the provision of homework support. Specifically, holding all other variables constant, a child's positive perception of the home environment increased the probability of parental involvement with the adolescent's homework by around 0.068 units. This effect is slightly higher for females (0.072) than for males (0.066). Computing elasticities in linear terms for the whole sample suggests that a $10 \%$ increase in home environment perception would have a significant $4.6 \%$ effect on parental involvement.

In the case of the full sample, most of the covariates capturing parental characteristics are not statistically significant. Only the number of years of difference between the adolescent and his or her mother is significant (and positive). Family structure (parents' civil status) did not have any impact on parental involvement, once the home environment had been included. Mother's educational level is hardly significant and only for those attaining secondary education. Thus, we cannot corroborate the existence of an educational gradient in child care (in this case, during adolescence). However, it is clearly and positively significant that homework assistance increases if the offspring receive a reward from his or her parents for doing homework. The model includes conscientiousness and motivation proxies as well school fixed effects.

Considering individual variables, age and being an immigrant reduces the probability that students receive homework assistance, whereas being female 


\begin{tabular}{|c|c|c|c|}
\hline & Full sample & Male students & Female students \\
\hline Household environment satisfaction & $0.068(0.01)^{\star \star \star}$ & $0.066(0.02)^{\star \star \star}$ & $0.072(0.02)^{\star \star \star}$ \\
\hline Age & $-0.051(0.02)^{\star \star}$ & $-0.074(0.04)^{\star *}$ & $-0.027(0.04)$ \\
\hline Being female & $0.082(0.03)^{\star \star \star}$ & & \\
\hline $\begin{array}{l}\text { Grade in mathematics past } \\
\text { academic year }\end{array}$ & $-0.050(0.01)^{\star * \star}$ & $-0.038(0.01)^{\star \star \star}$ & $-0.062(0.01)^{\star \star *}$ \\
\hline Being immigrant & $-0.151(0.05)^{\star \star \star}$ & $-0.175(0.07)^{\star \star \star}$ & $-0.129(0.06)^{\star \star}$ \\
\hline $\begin{array}{l}\text { Fourth academic year of compulsory } \\
\text { education (Grade 10) }\end{array}$ & $-0.057(0.04)$ & $-0.020(0.05)$ & $-0.102(0.06)^{\star}$ \\
\hline $\begin{array}{l}\text { Student states school notes should } \\
\text { be shared }\end{array}$ & $0.028(0.01)^{\star \star}$ & $0.054(0.02)^{\star \star}$ & $0.007(0.02)$ \\
\hline $\begin{array}{l}\text { Attending a publicly funded private } \\
\text { school or private school }\end{array}$ & $-0.534(0.14)^{\star \star \star}$ & $-0.103(0.16)$ & $-0.467(0.15)^{\star \star \star}$ \\
\hline Time to get to school & $0.001(0.00)$ & $0.001(0.00)$ & $0.000(0.00)$ \\
\hline Number of older siblings & $-0.042(0.03)$ & $-0.045(0.05)$ & $-0.036(0.04)$ \\
\hline $\begin{array}{l}\text { Parents' civil status: Not being } \\
\text { married }\end{array}$ & $0.024(0.05)$ & $-0.017(0.06)$ & $0.074(0.06)$ \\
\hline Number of years since divorce & $-0.005(0.01)$ & $-0.001(0.01)$ & $-0.010(0.01)$ \\
\hline Differential in years with mother & $0.007(0.00)^{\star \star \star}$ & $0.006(0.00)$ & $0.009(0.00)^{\star \star}$ \\
\hline $\begin{array}{l}\text { Mother's attaining secondary } \\
\text { education }\end{array}$ & $0.057(0.03)^{*}$ & $0.084(0.05)^{\star}$ & $0.033(0.04)$ \\
\hline Mother's attaining tertiary education & $0.044(0.03)$ & $0.072(0.06)$ & $0.008(0.04)$ \\
\hline $\begin{array}{l}\text { Number of books at home above } \\
100\end{array}$ & $0.017(0.03)$ & $-0.029(0.04)$ & $0.057(0.04)$ \\
\hline Father being employed & $0.067(0.05)$ & $0.101(0.07)$ & $0.013(0.08)$ \\
\hline Mother being employed & $-0.009(0.03)$ & $-0.014(0.04)$ & $-0.014(0.04)$ \\
\hline Father's health status degree & $-0.019(0.02)$ & $-0.013(0.03)$ & $-0.030(0.02)$ \\
\hline Mother's health status degree & $0.002(0.02)$ & $-0.013(0.03)$ & $0.033(0.03)$ \\
\hline $\begin{array}{l}\text { Receiving an award from parents for } \\
\text { doing homework }\end{array}$ & $0.066(0.01)^{\star \star \star}$ & $0.099(0.02)^{\star \star \star}$ & $0.044(0.02)^{\star *}$ \\
\hline $\begin{array}{l}\% \text { mother's attaining higher } \\
\text { education in the class }\end{array}$ & $0.199(0.14)$ & $0.160(0.17)$ & $0.452(0.20)^{\star \star}$ \\
\hline$\%$ immigrants in the class & $0.061(0.18)$ & $0.253(0.20)$ & $-0.044(0.27)$ \\
\hline$\%$ female classmates & $0.285(0.16)^{\star}$ & $0.426(0.23)^{\star}$ & $0.188(0.25)$ \\
\hline$\%$ divorced parents in the class & $-0.123(0.16)$ & $-0.173(0.19)$ & $-0.043(0.21)$ \\
\hline Conscientiousness factor & Yes & Yes & Yes \\
\hline Motivation factor & Yes & Yes & Yes \\
\hline School fixed effects & Yes & Yes & Yes \\
\hline$n$ & 2,113 & 998 & 1,115 \\
\hline Wald $\chi^{2}$ & $236.48(0.00)$ & $129.58(0.00)$ & $158.34(0.00)$ \\
\hline Pseudo $R^{2}$ & .0993 & .1172 & .1203 \\
\hline
\end{tabular}

Note. Adjusted robust standard errors for clustering at the classroom level are reported in parenthesis. ${ }^{*} p<.10 .{ }^{* \star} p<.05 .{ }^{* \star *} p<.01$.

increases the probability. As for school, the grade attained in mathematics in the previous academic year and attending any kind of private school also reduces the probability of receiving parental assistance. In addition, if students are of the opinion that school notes should be shared, then this increases the probability of receiving help with homework. Finally, in the case of class fixed effects, the higher the percentage of female classmates, the higher is the probability that students receive homework assistance.

In a subsequent step, we disentangled the sample in terms of gender to observe whether differential effects were to be found. In relation to our main variable of analysis, female students received greater homework support from their parents during adolescence. This is in line with reports of gender bias in parental effort (Bonesrønning, 2010).

An inspection of the rest of the descriptive statistics reveals other differences: age, whether students state that school notes should not be shared, mother's educational level, and the percentage of female classmates are only significant for males. In contrast, the year achieved in compulsory education, the type of school attended, differential years with the mother, and the percentage of mother's with higher education in the class are significant only for females.

Thus, the positive perception of the home environment among adolescents has a bearing on parental involvement in homework. In line with the theories that positively relate parental involvement with student achievement, our results show that the home environment is an important determinant of such involvement, especially for adolescent females. Therefore, the home environment would appear to be positively related 
to student achievement, confirming the conclusions of Todd and Wolpin (2007) for the Catalan case. Likewise, the inclusion of this variable makes other variables related to family structure hardly significant (or insignificant). Thus, adolescent perceptions of the home environment are more relevant than family structure or background in our analysis.

Table 4. Instrumental Variables Estimates for Students Receiving Assistance: Marginal Effects.

\begin{tabular}{lcc}
\hline & Regression 1 & Regression 2 \\
\hline Household environment satisfaction & $.180(.05)^{\star \star \star}$ & $.207(.05)^{\star \star \star}$ \\
$\begin{array}{l}\text { Share of classmates not receiving assistance and additional } \\
\quad \text { covariates }\end{array}$ & No & Yes \\
Individual and scholar covariates & Yes & Yes \\
Parental features & Yes & Yes \\
Conscientiousness factor & Yes & Yes \\
Motivation factor & Yes & Yes \\
School fixed effects & Yes & Yes \\
$N$ & 2,113 & 2,113 \\
Wald $\chi^{2}$ & $212.82(0.00)$ & $1,509.81(0.00)$ \\
Exogeneity test & $1.53(0.22)$ & $2.15(0.14)$ \\
\hline
\end{tabular}

Note. Adjusted robust standard errors for clustering at the classroom level are reported in parenthesis.

${ }^{*} p<.10 .{ }^{* \star} p<.05 .{ }^{* * *} p<.01$.

We further questioned the causal interpretation of our results. For this purpose, we adopted an IV approach as outlined in the "Data and Econometric Specification" section. Our instruments showed statistical significance in their explanatory power when explaining the home environment. With regard to the home environment estimates, our results revealed it to be a stronger determinant. In fact, the marginal effects were 3 times higher than those recorded previously (see Table 4, first column).

Finally, we included the percentage of classmates not receiving homework supervision as well as additional covariates that drive parent-adolescent relationships or that capture the impact of classmates and which were excluded from the previous estimates for reasons of efficiency. These factors were number of siblings, parents prohibiting children from going out too often, the number of students who nominated the student in question as a friend, the number of peers within the self-declared clique, the percentage of classmates likely to drop out, class size, and the percentage of classmates consuming marijuana. Our final results are shown in Table 4, column 2. Here again our main findings did not change. Results showed even higher effects of the home environment on parental effort compared with previous estimations.

\section{Conclusion}

This article has sought to explore the influence of the home environment, as opposed to that of family structure, on parental involvement in homework assistance during adolescence. In seeking to make a causal interpretation, we instrumented family environment to account for the presence of either unobservables or measurement errors.

Our findings serve to reinforce the relevance of the home environment on children's educational outcomes through an indirect channel (parental involvement). In this sense, our results are in line with the literature where it has been stressed that non-conflict helps students overcome adolescent educational failures (see Todd \& Wolpin, 2007). Hence, while family structure remained statistically non-significant, poor environments reduce parental involvement. Thus, student perception of the home environment is positively associated with parental involvement, with the effect being slightly higher for females than for males. The IV analysis confirms the reported results and shows that the home environment is an even stronger determinant of parental involvement.

The factors related to the home environment that are driving our results may be the following: On one hand, parents establish a home structure for learning (Feinstein \& Symons, 1999), pass on their children their educational goals and expectations (Jeynes, 2005), and generate a more positive attitude toward school (Gonzalez-DeHass, Willems, \& Holbein, 2005). On the other hand, parents establish a time management that allows active involvement with the education of their offspring (Flouri \& Buchanan, 2004), which includes not only helping with homework but also taking children to places and events that foster learning (Hill \& Tyson, 2009). All these factors allow a better home environment that affects parental involvement and fosters children's academic achievement, as our research shows. It has to be pointed out that these aspects that have a bearing on parental involvement at home may also increase parents' involvement at school, as part of parental involvement consists in parents' interaction with the schools (Hill et al., 2004), and benefit children's achievement (Hoover-Dempsey et al., 2001). 
Given the relevance of parental involvement in educational decisions and in a child's educational achievement, several policies need to be specifically addressed. Examples are related to responses to teachers' request (e.g., sign homework papers), parents' coaching initiatives to better involve their children in decision making and in the use of positive reinforcement, the creation of shared home-school goals for student learning, and so on (see a review in Hoover-Dempsey et al., 2001). In this sense, Avvisati, Gurgand, Guyon, and Maurin (2014) analyze a program of parent-school meetings discussing how to improve parental involvement in their children's education, with their positive effects for student attitudes and outcomes.

However, our study has several limitations. First, we consider the home environment as reported only by adolescents. Although the inclusion of the parents' point of view might well have reduced our sample, as it is difficult to persuade parents to complete questionnaires, and their inclusion might have biased the sample toward an over-representation of well-functioning families and teenagers (Weinberger, Tublin, Ford, \& Feldman, 1990), we believe that further research needs to include a measure of the family environment not only from the perception of the children but also from that of their parents. One option would be to obtain parental participation through more sophisticated measures such as the Family Environment Scale and, therefore, include both adolescent and parent perceptions in the analysis. In this respect, although Paulson and Sputa (1996) show that pupil ratings of parental involvement differ from those of their parents, Steinberg, Lamborn, Dornbusch, and Darling (1992) report that children are able to act as knowledgeable informants of parental behaviors and that they do not tend to exaggerate parental acceptance. Thus, we believe that the research will improve if parents' point of view is also taken into consideration but to exclude it is not a fatal flaw of the developed research.

Second, the article considers satisfaction with the home environment and not the home environment itself. Although the perception of a fact is used in some family analyses as a tool to describe the fact (see Daggett, O’Brien, Zanolli, \& Peyton, 2000), future research should consider a direct measurement of the home environment. Finally, the perception of the home environment is measured using only one item. In fact, other indicators related to the home environment are used (when the IV is constructed), such as the students' self-perception of their relationship with their father and mother. Our results show the statistical relevance of the home environment variable as well as that of the IV. However, an extension of the analysis should consider more complex measures of the home environment.

Despite the limitations of our study, it shows relevant results. First, there is a positive effect of the home environment on parental involvement in homework, which benefits students' achievement. Second, there are gender differences in the perception of this effect (female students have a higher perception). Third, home environment is a more relevant factor than the family structure. Finally, we highlight that the methodology used allows us to infer causality in the results.

\section{Declaration of Conflicting Interests}

The author(s) declared no potential conflicts of interest with respect to the research, authorship, and/or publication of this article.

\section{Funding}

The author(s) disclosed receipt of the following financial support for the research, authorship, and/or publication of this article: Toni Mora gratefully acknowledges the financial support of the Catalan Government (09SGR102-Generalitat de Catalunya).

\section{Supplementary Materials}

All data is available upon request.

\section{References}

Aldous, J. (2006). Family, ethnicity, and immigrant youths' educational achievements. Journal of Family Issues, 27, 1663-1667.

Alonso-Tapia, J., \& Arce-Sáez, E. (1992). Expectativas de control y motivación: el cuestionario ECO. In J. Alonso Tapia (Ed.), Motivar en la adolescencia: Teoría, evaluación e intervención (pp. 135-163). Madrid, Spain: Universidad Autónoma de Madrid.

Amato, P. R. (2000). The consequences of divorce for adults and children. Journal of Marriage and the Family, 62, 1269-1287.

Amato, P. R., \& Kane, J. B. (2011). Parents' marital distress, divorce, and remarriage: Links with daughters' early family formation transitions. Journal of Family Issues, 32, 1073-1103. 
Amato, P. R., \& Keith, B. (1991). Parental divorce and adult well-being: A meta-analysis. Journal of Marriage and the Family, 531, 43-58.

Amato, P. R., \& Sobolewski, J. (2001). The effects of divorce and marital discord on adult children's psychosocial well-being. American Sociological Review, 666, 900-921.

Avvisati, F., Gurgand, M., Guyon, N., \& Maurin, E. (2014). Getting parents involved: A field experiment in deprived schools. Review of Economic Studies, 81, 57-83.

Balli, S. J. (1998). When mom and dad help: Student reflections on parent involvement with homework. Journal of Research and Development in Education, 31, 142-146.

Bianchi, S. M. (2000). Maternal employment and time with children: Dramatic change or surprising continuity? Demography, 374, 401-414.

Bonesrønning, H. (2010). Are parental effort allocations biased by gender? Education Economics, 183, 253-268.

Boyce, C. J. (2010). Understanding fixed effects in human well-being. Journal of Economic Psychology, 311, 1-16.

Burnett, K., \& Farkas, G. (2009). Poverty and family structure effects on children's mathematics achievement: Estimates from random and fixed effects models. The Social Science Journal, 462, 297-318.

Canova, L., \& Vaglio, A. (2010). Why do educated mothers matter? A model of parental help (Working papers). Barcelona, Spain: XREAP.

Coleman, J. S., Campbell, E. Q., Hobson, C. J., McPartland, J., Mood, A. M., Weinfeld, F. D., \& York, R. L. (1966). Equality of educational opportunity. Washington, DC: National Center for Educational Statistics.

Cooper, H. (1989). Homework. New York, NY: Longman.

Cooper, H., \& Lindsay, J. J. (2000). Homework in the home: How student, family, and parenting-style differences relate to the homework process. Contemporary Educational Psychology, 25, 464-487.

Cooper, H., Robinson, J. C., \& Patall, E. A. (2006). Does homework improve academic achievement—A synthesis of research, 1987-2003. Review of Educational Research, 76, 1-62.

Crosnoe, R., \& Elder, G. H. (2004). Family dynamics, supportive relationships, and educational resilience during adolescence. Journal of Family Issues, 255, 571-602.

Daggett, J., O’Brien, M., Zanolli, K., \& Peyton, V. (2000). Parents’ attitudes about children: Associations with parental life histories and child-rearing quality. Journal of Family Psychology, 14, 187-199.

Dearing, E., Kreider, H., Simpkins, S., \& Weiss, H. B. (2006). Family involvement in school and low income children's literacy performance: Longitudinal associations between and within families. Journal of Educational Psychology, 98, 653-664.

De Fraja, G., Oliveira, T., \& Zanchi, L. (2010). Must try harder: Evaluating the role of effort in educational attainment. The Review of Economics and Statistics, 923, 577-597.

Deslandes, R., \& Cloutier, R. (2002). Adolescents' perception of parental involvement in schooling. School Psychology International, 23, 220-232.

Di Pietro, G., \& Cutillo, A. (2006). Does attending a Catholic school make a difference? Evidence from Italy. Bulletin of Economic Research, 583, 193-234.

Dotterer, A. M., Hoffman, L., Crouter, A. C., \& McHale, S. M. (2008). Longitudinal examination of the bidirectional links between academic achievement and parent-adolescent conflict. Journal of Family Issues, 296, 762-779.

Duchesne, S., \& Ratelle, C. (2010). Parental behaviors and adolescents' achievement goals at the beginning of middle school: Emotional problems as potential mediators. Journal of Educational Psychology, 101, 497-507.

Duffet, A., \& Johnson, J. (2004). All work and no play? Listening to what kids and parents really want from out-ofschool time: A report from Public Agenda. New York, NY: Public Agenda.

Feinstein, L., \& Symons, J. (1999). Attainment in secondary school. Oxford Economic Papers, 51, 300-321.

Flouri, E., \& Buchanan, A. (2004). Early father's and mother's involvement and child's later educational outcomes. British Journal of Educational Psychology, 74, 141-153.

Francesconi, M., Jenkins, S. P., \& Siedler, T. (2010). Childhood family structure and schooling outcomes: Evidence for Germany. Journal of Population Economics, 233, 1201-1231.

Frome, P. M., \& Eccles, J. S. (1998). Parents' influence on children's achievement related perceptions. Journal of Personality and Social Psychology, 74, 435-452.

Gelber, A., \& Isen, A. (2013). Children's schooling and parents' behavior: Evidence from the head start impact study. Journal of Public Economics, 101, 25-38.

Ginther, D. K., \& Pollak, R. A. (2004). Family structure and children's educational outcomes: Blended families, stylized facts, and descriptive regressions. Demography, 414, 671-696.

Gonzalez-DeHass, A. R., Willems, P. P., \& Holbein, M. F. D. (2005). Examining the relationship between parental involvement and student motivation. Educational Psychology Review, 17, 99-123.

Grolnick, W. S., \& Ryan, R. M. (1989). Parent styles associated with children’s self-regulation and competence in school. Journal of Educational Psychology, 81, 143-154.

Guryan, J., Hurst, E., \& Kearney, M. (2008). Parental education and parental time with children. Journal of Economic Perspectives, 223, 23-46.

Gutiérrez-Domènech, M. (2010). Parental employment and time with children in Spain. Review of Economics of the Household, 8, 371-391.

Hill, N. E., Castellino, D. R., Lansford, J. E., Nowlin, P., Dodge, K. A., Bates, J. E., \& Pettit, G. S. (2004). Parent academic involvement as related to school behavior, achievement, and aspirations: Demographic variations across adolescence. Child Development, 75, 1491-1509.

Hill, N. E., \& Tyson, D. F. (2009). Parental involvement in middle school: A meta-analytic assessment of the strategies that promote achievement. Developmental Psychology, 45, 740-763. 
Holmlund, H., Lindahl, M., \& Plug, E. (2011). Causal effect of parents' schooling on children's schooling. Journal of Economic Literature, 493, 615-651.

Hoover-Dempsey, K. V., Battiato, A. C., Walker, J. M., Reed, R. P., DeJong, J., \& Jones, K. P. (2001). Parental involvement in homework. Educational Psychologist, 363, 195-209.

Houtenville, A. J., \& Conway, K. S. (2008). Parental effort, school resources and student achievement. Journal of Human Resources, 432, 437-453.

Irwin, C. E., Scott, J. B., \& Uhler, C. (2002). America's adolescents: Where have we been, where are we going? Journal of Adolescent Health, 316, 91-121.

Irwin, S. (2009). Family contexts, norms and young people’s orientations: Researching diversity. Journal of Youth Studies, 12, 337-354.

Jeynes, W. (2005). A meta-analysis of the relation of parental involvement to urban elementary school student academic achievement. Urban Education, 40, 237-269.

Johnson, T. S., \& McComb, E. M. (2008). Homework help in afterschool programs: Literature review. Greensboro: SERVE Center at the University of North Carolina.

Jones, J. T., Toma, E. F., \& Zimmer, R. W. (2008). School attendance and district and school size. Economics of Education Review, 272, 140-148.

Katz, I., Kaplan, A., \& Buzukashvily, T. (2011). The role of parents' motivation in students' autonomous motivation for doing homework. Learning and Individual Differences, 21, 376-386.

Kristjansson, A. L., \& Sigfusdottir, I. D. (2009). The role of parental support, parental monitoring, and time spent with parents in adolescent academic achievement in Iceland: A structural model of gender differences. Scandinavian Journal of Educational Research, 53, 481-496.

Lansford, J. E. (2009). Parental divorce and children's adjustment. Perspectives on Psychological Science, 42, 140152.

Leaper, C. (2000). Gender, affiliation, assertion, and the interactive context of parent-child play. Developmental Psychology, 36, 381-393.

Leone, C. M., \& Richards, M. H. (1989). Classwork and homework in early adolescence: The ecology of achievement. Journal of Youth and Adolescence, 18, 531-548.

Linver, M., Barber, B. L., \& Eccles, J. S. (1997). Parents make a difference: Influences on adolescents' college graduation plans. Presented at the annual meeting of the American Educational Research Association, Chicago, IL

Melby, J., \& Conger, R. D. (1996). Parental behaviors and adolescent academic performance: A longitudinal analysis. Journal of Research on Adolescence, 6, 113-137.

Milgram, N. A., \& Toubiana, Y. (1999). Academic anxiety, academic procrastination, and parental involvement in students and their parents. British Journal of Educational Psychology, 693, 345-361.

Morrow, V. (2006). Understanding gender differences in context: Implications for young children's everyday lives. Children \& Society, 20, 92-104.

Musick, K., \& Meier, A. (2010). Are both parents always better than one? Parental conflict and young adult well-being. Social Science Research, 395, 814-830.

Norman, W. (1963). Toward an adequate taxonomy of personality attributes: Replicated factor structure in peer nomination personality ratings. Journal of Abnormal and Social Psychology, 66, 576-583.

Oubrayrie-Roussel, N., \& Safont-Mottay, C. (2011). Adolescent homework management strategies and perceptions of parental involvement. International Journal About Parents in Education, 5, 78-85.

Patall, E. A., Cooper, H., \& Robinson, J. C. (2008). Parent involvement in homework: A research synthesis. Review of Educational Research, 784, 1039-1101.

Paulson, S. E., \& Sputa, C. L. (1996). Patterns of parenting during adolescence: Perceptions of adolescents and parents. Adolescence, 31, 369-381.

Rønning, M. (2011). Who benefits from homework assignments? Economics of Education Review, 301, 55-64.

Sanz-de-Galdeano, A., \& Vuri, D. (2007). Parental divorce and students' performance: Evidence from longitudinal data. Oxford Bulletin of Economics and Statistics, 693, 321-338.

Sayer, L. C., Bianchi, S. M., \& Robinson, J. (2004). Are parents investing less in children? Trends in mothers' and fathers' time with children. American Journal of Sociology, 1101, 1-43.

Shek, D. T. L. (1999). Parenting characteristics and adolescent psychological well-being: A longitudinal study in a Chinese context. Genetic, Social, and General Psychology Monographs, 125, 27-44.

Shumow, L. (1998). Promoting parental attunement to children's mathematical reasoning through parent education. Journal of Applied Developmental Psychology, 19, 109-127.

Sorbring, E., Rödholm-Funnemark, M., \& Palmérus, K. M. (2003). Boys’ and girls’ perceptions of parental discipline in transgression situations. Infant and Child Development, 12, 53-69.

Steinberg, L., Lamborn, S. D., Dornbusch, S. M., \& Darling, N. (1992). Impact of parenting practices on adolescent achievement: Authoritative parenting, school involvement, and encouragement to succeed. Child Development, 63, 1266-1281.

Teachman, J. D. (2008). The living arrangements of children and their educational well-being. Journal of Family Issues, 296, 734-761.

Todd, P. E., \& Wolpin, K. I. (2007). The production of cognitive achievement in children: Home, school, and racial test score gaps. Journal of Human Capital, 11, 91-136.

Turtiainen, P., Karvonen, S., \& Rahkonen, O. (2007). All in the family? The structure and meaning of family life among young people. Journal of Youth Studies, 10, 477-493.

Walsh, P. (2010). Is parental involvement lower at larger schools? Economics of Education Review, 29, 959-970. 
Weinberger, D., Tublin, S., Ford, M., \& Feldman, S. (1990). Preadolescents' social-emotional adjustment and selective attrition in family research. Child Development, 61, 1374-1386. 